\title{
E-Learning in the Linguistic Disciplines Teaching: the Experience of Remote and Full- Time Learning
}

\author{
Tatiana Isaeva* \\ Rostov State Transport University, 344038, 2, Rostovskogo Strelkovogo Polka Narodnogo \\ Opolcheniya Sq., Rostov-on-Don, Russia
}

\begin{abstract}
The period of forced remote learning has deepened university teachers' and students' experience in e-learning and developed a number of abilities, including ITC-competence and possession of various e-learning methods. This valuable experience should be used after resuming of fulltime or face-to-face (F2F) learning in the universities. The purpose of the article is to determine the most promising areas of using e-learning in the linguistic disciplines teaching based on the analysis of the advanced teaching experience during the pandemic and after the resumption of traditional fulltime education. Using the methods of theoretical analysis of the scientific works published within the period February 2020 - February 2021 and empirical study among Russian university teachers and students, the most efficient and promising areas of e-learning in the linguistic disciplines teaching were singled out. These areas include the use of the efficient elearning methods and creation of lasting online learning communities. At the same time the empirical survey showed one more important area of research, namely, the characteristics of the teacher's speech in distance education. In the result, the author suggests some ideas to preserve the valuable obtained teaching experience and to use it in both forms of learning: distance and F2F.
\end{abstract}

\section{Introduction}

Over the past two years, university teachers of linguistic disciplines have gained valuable and varied experience in conducting classes using information and communication technologies (ICT) in the conditions of forced remote learning caused by the COVID-19 pandemic and traditional face-to-face education (F2F) before and after the restrictions abolition in the universities of the Russian Federation.

E-learning is characterized by such features as flexibility, integrity, interactivity, unlimited space for creating communication situations, synchronous and asynchronous educational interaction [1], which are a great advantage for studying foreign languages and other linguistic disciplines at the university. However, it was the first period in educational history when all the lessons, lectures and even practical classes were conducted with the help of electronic means of communication.

\footnotetext{
* Corresponding author: isaeva.te@yandex.ru
} 
Special conditions for educational interaction $[2 ; 3]$, incomplete readiness both in terms of technical equipment that universities could provide $[4 ; 5]$ and methodical competence of university teachers $[5 ; 6]$, the low validity of the procedures for assessing learning outcomes [4], the emotional stress suffered by the participants of the educational process [7], etc. are reflected in many scientific articles, the authors of which have come to the logical conclusion that remote learning is a temporary measure due to a threat to the health and safety of people all over the world, therefore, this stage in the history of higher education should be regarded as a time-limited, forced period with numerous shortcomings and limitations that need to be corrected after the resumption of "normal", i.e. F2F learning environment [5; 8].

However, it should not be forgotten that it was during this period that the skills and competences of teachers and students in the use of ICT have significantly increased, and new technical and methodical solutions appeared that allow combining full-time and distance learning, organize group and individual interaction of teachers with students in the modes of synchronous and asynchronous learning [4;8]. During the same period, university research and teaching staff have enriched their methodical experience in preparing and conducting webinars, using electronic teaching aids, online courses, participating in scientific conferences through electronic conference platforms, etc. [2; 4].

Therefore, the purpose of this article is to determine the most promising areas of using elearning in the linguistic disciplines teaching based on the analysis of the advanced Russian and foreign experience during the pandemic and after the resumption of traditional full-time education.

\section{Materials and Methods}

The study was conducted over a year period, starting in February 2020, when the universities of the Russian Federation were forced to switch to remote learning, and until March 2021, i.e. the stage of lifting the strict restrictions caused by the pandemic and returning to the traditional full-time educational regime.

During this entire period, the following research methods were used:

- analysis of theoretical scientific publications on the problems of organizing remote learning caused by the COVID-19 pandemic, establishing pedagogical interaction, identifying the features of training communication in foreign language and using traditional methods and technologies for the formation of students' communicative competence in distance conditions, as well as new requirements for the teacher's speech technique, possession of speech technique and para-speech skills when conducting online classes;

- empirical research methods: observation, survey (and the survey was conducted both in conversational mode and by means of electronic conference platforms Skype, Zoom, Microsoft Teams);

- methods of statistical processing of the obtained data and visual presentation of research results.

More than 40 teachers from leading Russian universities and 158 students of all educational levels (bachelors, masters, and postgraduate students) took part in the survey.

Due to the fact that in the course of the work empirical research methods were used in relation to undergraduate, graduate and postgraduate students, as well as to university faculty teaching at all these levels, we have chosen the term "the linguistic disciplines" to mention all disciplines related to teaching foreign languages in higher educational institutions,

The competence-based and personality-cantered approaches were chosen as a research methodology, suggesting the priority of the tasks of the students' personal development, taking into account their inclinations, interests and abilities when choosing the content and methods of teaching, as well as the use of interactive methods and learning technologies to involve students in the process of information search, processing and conscious assimilation. 


\section{Results}

\subsection{Identification of the most promising areas of using e-learning in the linguistic disciplines teaching}

In order to generalize the advanced e-learning pedagogical experience of teachers of the linguistic disciplines in universities around the world and determine the most popular areas of research in this field, the analysis of scientific publications of Russian and foreign scientists within the period February 2020 - February 2021 was carried out [2 - 9]. For the same purpose, a survey was organized among the university faculty teaching foreign language classes in a number of universities of Moscow, Rostov-on-Don, Novosibirsk, Krasnodar, Taganrog. As a result, it became possible to identify areas of e-learning that teachers consider the most effective, optimal and promising both for use in F2F and distance / remote learning. The data obtained are presented in table 1 .

Table 1. The most promising areas of e-learning in the linguistic disciplines teaching.

\begin{tabular}{|c|c|c|}
\hline Areas of e-learning & $\begin{array}{c}\text { The percentage of } \\
\text { preference }\end{array}$ & $\begin{array}{l}\text { The most popular } \\
\text { aspect of the area }\end{array}$ \\
\hline $\begin{array}{l}\text { Educational interaction by means of } \\
\text { conference-platforms (Zoom, Microsoft } \\
\text { Teams, Moodle, Skype, etc.) }\end{array}$ & r & Zoom $-62 \%$ \\
\hline $\begin{array}{l}\text { Additional resources of e-learning } \\
\text { (online-courses, YouTube, social } \\
\text { networks, etc.) that can be used both as } \\
\text { extracurricular activities and classroom } \\
\text { electronic means of education }\end{array}$ & 78 & YouTube - 54\% \\
\hline $\begin{array}{l}\text { Online-education by means of } \\
\text { university electronic information-and- } \\
\text { educative environment }\end{array}$ & 64 & $\begin{array}{l}\text { Online-lessons - } \\
52 \%\end{array}$ \\
\hline $\begin{array}{c}\text { Creation of the online learning } \\
\text { communities }\end{array}$ & 55 & $\begin{array}{c}\text { Learning } \\
\text { communities in } \\
\text { Facebook }-45 \%\end{array}$ \\
\hline $\begin{array}{l}\text { Simulation technologies and business } \\
\text { simulators }\end{array}$ & 35 & $\begin{array}{l}\text { Game simulators } \\
\text { connected with } \\
\text { students' future } \\
\text { profession }-22 \%\end{array}$ \\
\hline
\end{tabular}

\subsection{Determination of the most efficient teaching methods and technologies at the linguistic cycle lessons}

Usually, speaking about the system of methods that are currently used in the linguistic disciplines teaching, it is customary to mention:

1) traditional methods (for example, methods of explaining vocabulary or training grammatical skills in exercises, etc.);

2) interactive methods (role play, discussion, simulation, case method, project learning, etc.);

3) e-learning methods based on the use of various electronic teaching aids, electronic tools, Internet resources, etc.

In this article, in accordance with the design of the study, we will focus on the third group.

It is customary to enumerate as e-learning methods: training methods, demonstration methods, problem solving methods, team working methods, blogging technology, and creative research methods [1]; demonstration, illustration, explanation, story, conversation, 
exercise, problem solving, memorizing educational material, writing, and repetition [8] simulation technology and game simulation; concrete experience, reflective observation, abstract conceptualization, and active experimentation in virtual educational reality [9], etc.

Training methods in e-learning are advantageous because they offer unlimited opportunities for every student who can choose a number of training drills, time period of repetitions, intensity and systematic character of exercising.

Demonstration methods within e-learning occupies an extremely significant role in linguistic disciplines teaching as new information technologies make it possible to demonstrate linguistic and polycultural information of any nature and in any form: pictures, slides, objects, texts, vocabulary, grammar, audio, video, graphics, etc.

Problem solving and team working methods can be joined because they help to organise group communication that is the closest variant to the authentic linguistic environment. Moreover, these methods are of great value in the process of social adaptation, formation of characteristics of a leader, the managerial and monitoring skills.

All methods that deal with social networks and hostings (blogging technology, YouTube, Facebook, etc.) are very efficient as they create learning communities, enrich individual outlook and cultural perception. They can motivate a person to develop linguistic skills in extracurricular time by finding information, video and even through engagement into a real communication with foreigners. These methods are also can be considered as creative ones, because they give a person an opportunity for self-expression and self-realization.

The methods (Multimedia Scrapbook, Treasure Hunt (Hunt for wealth), WebQuest (Web search), game and professional simulators, etc.) that teach a student to navigate in a vast information flow in order to find the necessary information provide him/her with the skills and competences especially required for the specialist of digital economy.

\subsection{Creation of the online learning communities}

Online learning communities have existed long before the pandemic [10]. However, when the teachers and students faced the necessity of acquisition of new knowledge, skills and competences within the unprecedentedly short period when all the universities were transferred to remote learning in March, 2020, it gave the impulse for spontaneous emergence of a new type of online learning communities. It was characterized by a volunteering attitude towards participation, being free of official registration and other boring procedures, due to a shared conscientious approach to professional / learning duties, common social concern and common understanding of personal lack of competences in the situation of uncertainty.

In general, we single out the following types of online learning communities:

1) officially created online learning communities with a purpose of getting knowledge and skills according to certain programmes, which are mainly addressed for those participants who want to get education and vocational training but do not have resources in the region of their dwelling;

2) spontaneously created online learning communities, which include both teachers and students to solve specific goals (insufficient knowledge of using conference platforms Zoom, Microsoft Teams, etc., lack of experience in planning classes or recording classes on these platforms, etc.);

3) constantly operating online learning communities pursuing the aim to develop certain competences and improve existing knowledge, for example: discussion clubs, interest groups, communities interested in the culture of foreign countries, music, films, etc.

Naturally, such communities can choose various technical resources for their functioning: the electronic educational environment of the university, for example, for online interaction of teachers and students who share common cultural and linguistic interests, or the possibilities of social networks and media resources. 
In order to identify the reasons of the online learning communities created during the pandemic, we asked teachers and students three questions:

1. Did you seek advice from teachers / students on issues not related to educational material, but caused by difficulties in using electronic teaching aids, ICTtechnologies, working on conference platforms, etc.?

2. Have you ever encountered situations when the discussion of any issues of culture, politics, music, films, etc. in the classroom in the linguistic disciplines led to the desire to continue communication outside the classroom and with the help of partners, people belonging to a different culture?

3. Do you consider it useful to preserve the experience of communication in the online learning community, acquired during the period of distance learning, for the development of the missing skills and competences in the conditions of F2F learning?

$96 \%$ of respondents, both teachers and students, answered the first question positively, noting the difficulties in organizing distance learning, especially during the first weeks of this process. Basically, these difficulties were associated with the lack of special training or methodical instructions developed by the university for working on new conference platforms and using all their tools in the educational process.

Answering the second question, $56 \%$ of the survey participants noted that in the past, the environment in the classrooms did not allow them to deviate from the topics stated in the curriculum, so they almost never talked to students about their hobbies or did not show their home collections to their colleagues. But due to the fact that during e-learning, interior items often fell into the visibility of the webcam, there was a desire to discuss them with communication partners, and as a result, many participants of the educational process found that their students or teachers have exciting hobbies, they share one's interest in music, art, etc.

In addition, $48 \%$ of the respondents noted that due to the fact that online classes were not as formal as traditional ones, sometimes for relaxation, a teacher or students suggested listening to a melody or shared recently received information, as a result, interest groups arose. whose participants expressed a desire to continue communication after classes.

Finding themselves in rather limited conditions due to lockdown and social limitation, the participants of the educational process, as well as people all over the planet, began to look for people sharing their interests among inhabitants of other countries. The most popular social network for communication in a foreign language, according to $45 \%$ of respondents, is Facebook. Teachers and students enthusiastically shared new emotions and knowledge gained in the course of communication with foreigners who speak the foreign language they are studying. Many people who have established contacts with foreign partners would like to continue them, although they realize that returning to a "normal" lifestyle will significantly shorten their spare time.

In relation to the third question, the opinions of teachers and students were divided: more than $60 \%$ of teachers do not mind continuing online communication with colleagues or students in order to develop their professional and personal competences, as well as finding people who share their interests. However, more than $80 \%$ of students noted that their willingness to participate in the activities of the online learning community was due to limited contacts with peers, a fairly free regime of the day due to the absence of the need to use transport, attend sports sections, etc. therefore, they expressed doubt that they would continue to communicate with teachers and other students online. 


\subsection{Features of the teacher's speech in distance learning}

Although the question about the peculiarities of the teacher's speech in e-learning was not raised by us in this study, it should also be given attention, since more than $60 \%$ of respondents raised it during the survey.

The interviewed teachers identified the following aspects that are typical for conducting online classes and concerning the issues of mastering a pedagogical voice, voice flexibility, speech intonation, emotional colouring of speech and other components of speech technique, which fully correspond to the results of the studies $[2 ; 10 ; 11 ; 12]$ :

- excessive tension of the vocal cords, the development of fatigue and overexertion after 3-4 hours of teaching;

- difficulties in maintaining an emotional mood in the conditions when students are present at the lesson with the webcams turned off, i.e. in the absence of visual contact with interlocutors;

- the need to change the content of the speech: to make their statements shorter, "thesislike", better memorable and consistent with the demonstrated presentations or online courses;

- certain limitations in e-learning conference-platforms for a quick change in the speech mode (individual, pair, group, frontal).

In their turn, the students noted that:

- the teachers' speech during lectures is often faster than in the classroom;

- many teachers give lectures unemotionally, "on one note", that is why students' interest in the perception of the material is rapidly falling;

- it is difficult to perceive any, even the most interesting teacher for more than one hour, since it is physically difficult to sit in front of a computer for a long time without interruption;

- sometimes the teachers get very angry and switch to a raised voice tone because of technical failures or if they could not immediately get the correct answer from the student.

The most popular answers are summarized in Chart 1.

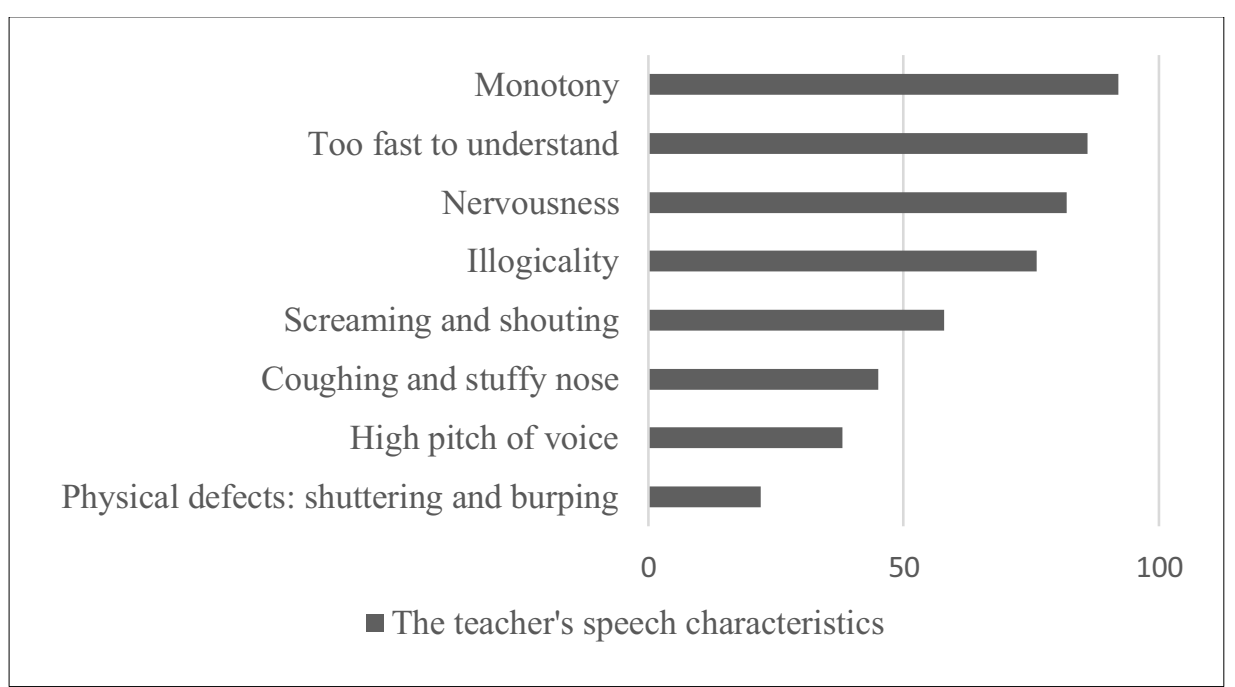

Fig. 1. The teacher's speech characteristics, which decrease e-learning efficiency

Thus, further research of the features of university teachers' speech behaviour in elearning is required. 


\section{Discussion}

Despite a rather short period of forced remote learning, which lasted in higher educational institutions of the Russian Federation during the spring and autumn semesters of 2020, research and teaching staff acquired significant methodical experience in organizing remote interaction with students, which can be used in the future. It becomes essential for the conditions of F2F training, as it makes it possible to use modern electronic teaching aids and e-learning methods in the classroom. As the first months after the resumption of full-time educational contacts show, teachers now prefer to check students' home assignment outside of the classroom and conduct it through synchronous or asynchronous interaction (to check, e.g., written assignments).

However, in the course of distance learning, some theoretical and practical questions arose that require further research:

1) Study of the methods for conducting traditional forms of classes (lecture, practical lesson, laboratory lesson) and new forms that have appeared due to the introduction of elearning (webinar, online lecture, online seminar, online exam, etc.);

2) further research of the features of the university teacher's speech behaviour has become acute.

\section{Conclusions}

The results of the analysis of scientific publications and the answers of the respondents convincingly prove that:

1) the range of using e-learning in the process of teaching linguistic disciplines has expanded significantly;

2) students and teachers have mastered new electronic means and learning resources, and the process of mastering foreign languages received a powerful impetus due to the introduction of new original content into the educational process;

3) the formation of competences for searching and processing information, as well as communicative and various social competencies, which are considered necessary for specialists in the digital economy: these competences expand the educational value of linguistic disciplines in the course of training the students of all programs and specialties;

4) the motivation of students to study linguistic disciplines has increased due to enriching the content of the lessons with "modern", "youth" content that meets their interests and is able to add some variety to the content of the educational material.

However, at the same time, the experience of remote learning and the first months of the transition to full-time education posed a number of tasks for the global academic community that require immediate theoretical and practical solutions:

1. The technical equipment of classrooms at the universities must meet the ambitious goals of training specialists for the digital economy. Returning to the walls of the university, students should not be disappointed that the material base of the university (modern computers, equipment of linguistic laboratories, access to the Internet, availability of wi-fi, etc.) is inferior to the level of e-learning to which they managed to get used to during the period of remote learning.

2. It is necessary to organize a permanent system of professional development for teachers, during which they will have the opportunity to get acquainted and study the advanced pedagogical experience of their colleagues from different countries of the world, accumulated during the period of social isolation.

3. Due to the fact that pedagogical communication, the speech of the teacher and students in the conditions of distance learning has its own characteristics and limitations associated with the lack of habitual eye contact with the audience, research is required in this field. The 
situation is worsened by physiological and psychological difficulties caused by prolonged work on a computer or with other electronic gadgets.

\section{References}

1. Ju. Shishkovskaya, D. Bakalo, A. Grigoryev, Procedia-Social and Behavioral Sciences 206, 199 - 204 (2015).

2. S.I. Kuzina, I.G. Sagiryan, E.A. Krasnova, V.K. Barashyan, ISC 2019. Lecture Notes in Networks and Systems, 198 (2021) .

3. E. Rudenko, R. Bachieva, A. Aligadzhieva et al. ITSE-2020. E3S Web of Conferences 210, 18038 (2020).

4. L. DS. Lapitan, C. E. Tiangco, D. A. Sumalinog, Education for Chemical Engineers 35, 116-131 (2021).

5. A. Reznikova, T. Kudinova et al. ITSE-2020. E3S Web of Conferences 210, 18037 (2020).

6. T. Isaeva, N. Malishevskaya et al. ITSE-2020. E3S Web of Conferences 210, 18071 (2020).

7. S. Shafaq, Sh. A. A. Shah, F. Memo et al. Revista de Psicodidáctica. PSICOD-85, 2-10 (2020).

8. O. Yarovaya, L. Yarovaya, and E. Bogatskaya, ITSE-2020. E3S Web of Conferences 210, 18051 (2020).

9. J. Fromm, J. Radianti, Ch.Wehking et al. The Internet and Higher Education, 100804 (2021).

10. M.A. Sukhomlinova, Bull. Volgograd State Pedagogical Univ. 6(139), 172-178 (2019).

11. T.V. Kustov, A.V. Timofeev, N.V. Tokarev, Mod. Educ.: Content, Technol. Qual. 2, 6265 (2018).

12. M. S. Lal Khan, Sh. q ur Réhman, Procedia Manufacturing 3, 2034 - 2041 (2015). 